\title{
Crosslinguistic Developmental Consistency in the Composition of Toddlers' Internal State Vocabulary: Evidence from Four Languages
}

\author{
Susanne Kristen, ${ }^{1}$ Sabrina Chiarella, ${ }^{2}$ Beate Sodian, ${ }^{1}$ \\ Tiziana Aureli, ${ }^{3}$ Maria Genco, ${ }^{3}$ and Diane Poulin-Dubois ${ }^{2}$ \\ ${ }^{1}$ Ludwig-Maximilians University, 80802 Munich, Germany \\ ${ }^{2}$ Concordia University, Montréal, QC, Canada H4B 1R6 \\ ${ }^{3}$ The "G. d’Annunzio" University of Chieti-Pescara, 66100 Chieti, Italy \\ Correspondence should be addressed to Susanne Kristen; susanne.kristen@psy.lmu.de
}

Received 14 June 2014; Accepted 28 July 2014; Published 21 August 2014

Academic Editor: Glenda Andrews

Copyright (C) 2014 Susanne Kristen et al. This is an open access article distributed under the Creative Commons Attribution License, which permits unrestricted use, distribution, and reproduction in any medium, provided the original work is properly cited.

\begin{abstract}
Mental state language, emerging in the second and third years of life in typically developing children, is one of the first signs of an explicit psychological understanding. While mental state vocabulary may serve a variety of conversational functions in discourse and thus might not always indicate psychological comprehension, there is evidence for genuine references to mental states (desires, knowledge, beliefs, and emotions) early in development across languages. This present study presents parental questionnaire data on the composition of 297 toddler-aged (30-to 32-month-olds) children's internal state vocabulary in four languages: Italian, German, English, and French. The results demonstrated that across languages expressions for physiological states (e.g., hungry and tired) were among the most varied, while children's vocabulary for cognitive entities (e.g., know and think) proved to be least varied. Further, consistent with studies on children's comprehension of these concepts, across languages children's mastery of volition terms (e.g., like to do and want) preceded their mastery of cognition terms. These findings confirm the cross-linguistic consistency of children's emerging expression of abstract psychological concepts.
\end{abstract}

\section{Introduction}

From an early age, children label their own as well as others' sensations, perceptions, and epistemic states. Studies show that early talk about internal states (ISL) is related to precursor abilities of a theory of mind (ToM) (e.g., perspective taking) [1]. It might thus be used as an indicator of children's early ToM, that is, children's understanding of their own and others' psychological world. It seems even possible that assessment of internal state language could be used to measure the developmental progression of early childhood ToM. This may be of great value as a complement to standard ToM tasks in different research contexts. Note that so far instruments such as the ToM scale developed by Wellman and Liu [2] are not usable for children younger than 3 years of age.

In regard to what is known about the development of internal state talk, this ability to talk about the mind begins to emerge late in the second year of life with a rapid spurt in the third year of life [3]. Based on findings derived from an extensive literature review on children's internal state words and natural speech samples of a cohort of 20month-olds, Bretherton and colleagues [3] concluded that children up to 36 months of age produced mental state words from six categories: perception (e.g., hear, taste), physiology (e.g., hungry, tired), affect/emotion (e.g., happy, sad), volition/ability (e.g., need, can), moral judgment/obligation terms (e.g., good, supposed to do), and cognition terms (e.g., know, think) [3]. Following up on these findings, Bretherton and Beeghly [4] asked 30 mothers to document the internal state word utterances of their 28-month-olds and created a 78-word checklist for assessing toddlers' internal state word production, the Internal State Language Questionnaire (ISLQ). The authors found that at that age children produced on average 37.2 words from the checklist (48\%). 
Specifically, at 28 months, children produced perceptual (69\%), volition/ability (69\%), and physiological (64\%) words the most, followed by emotional (46\%) and moral (44\%) words, with cognition (28\%) words being produced the least. The relatively late emergence of cognitive words was also documented by Shatz and her colleagues who examined two-and-a-half- to four-year-olds and noted that cognitive terms were most often used by children in the third year and used for pragmatic conversational functions [5]. In a longitudinal study by Bartsch and Wellman [6], 10 children were followed from the age of 18 months to five years during which their internal state language utterances were examined. From the everyday conversations that were collected from the CHILDES database, the authors found that among the 200,000 collected utterances, 12,000 included inner state terms and could be classified into two major categories: thought and belief terms (e.g., think, know) and desire terms (e.g., want, wish). Desire terms began to be produced between 18 and 24 months of age, whereas belief terms emerged only around the third year. The findings also revealed that thought and belief terms only began to match the frequencies of the desire terms at five years of age.

While references to inner states can be found in all languages, the bulk of the published research has focused on English speakers. Nevertheless, the development of desire terms before belief terms has also been reported in the speech of children who speak languages other than English, including Spanish, Mandarin, Cantonese, and French children [710]. To date, only one study has directly compared linguistic groups on the entire range of internal state word categories. In 32-month-old English- and French-Canadian children, Poulin-Dubois et al. [9] found a developmental sequence similar to Bretherton and Beeghly [4]. Across languages, children produced more perceptual (78\%) terms followed by physiological (69\%), volition/ability (68\%), and emotional (67\%) words, with moral (52\%) and cognitive (38\%) words lagging significantly behind all other word categories. Taken together, the findings from Poulin-Dubois and her colleagues provided the first evidence that the distribution of internal state words is similar across languages.

To replicate and extend these findings it seems crucial to compare yet larger samples of children speaking different languages in regard to the composition of their vocabulary for internal states. How similar, or different, is the composition of children's internal state term vocabulary across languages from a range of Western cultural groups? Thus, the current study aimed to explore crosslinguistic consistency in the size of and in the composition of internal state vocabulary in a sample of Italian-, German-, English-, and French-speaking children. Based on previous research, children's mental lexicon at 30 months was hypothesized to be especially rich in physiological, volitional, perceptual, and emotional terms, while children's vocabulary for moral and obligation terms was expected to be less varied across languages. Finally, children's cognition vocabulary was expected to be less varied. More specifically, it was expected that, across all languages, children's desire and ability terms would be more varied than their cognition terms.

\section{Method}

2.1. Participants. The sample included 297 participants (147 females): 64 Italian children (37 females), 68 German children (33 females), 91 English-Canadian children ( 43 females), and 74 French-Canadian children (34 females). Further demographic information can be found in Table 1 . Note that in the English-Canadian sample $n=7$ mothers and in the French-Canadian sample $n=4$ mothers did not indicate their educational level.

Both French- and English-speaking participants were recruited from birth lists provided by a government health agency in Montréal, Canada. When children were on average 32 months of age the families were sent either the English or French version of ISLQ, in accordance with the primary language spoken at home. German children were originally recruited using birth lists as part of a longitudinal study on precursor abilities of a theory of mind and mothers filled out the German adaptation of the ISLQ when children were tested at the Infant Laboratory at the University of Munich at 30 months of age. Italian children and their mothers were recruited from hospital records and mothers filled out the Italian version of the ISLQ when their 30-month-olds were tested at the Infant Laboratory at the University of ChietiPescara.

2.2. Measure. The ISLQ [11] used in this study was adapted from Bretherton and Beeghly [4] and includes a checklist of 78 words divided into 6 different categories, more specifically (1) physiology (e.g., hungry, tired), (2) volition/ability (e.g., want, can), (3) perception (e.g., see, look), (4) emotion/affect (e.g., happy, nice), (5) moral judgment/obligation (e.g., good, must), and (6) cognition (e.g., know, understand). Parents were given written instructions to check off as many words as they had heard their child say. The Italian, German, and French versions were adapted from the English original version in order to obtain a representative list of commonly used internal state terms in each category for each language. Not all items from the English questionnaire had translation equivalents in each language. Further, in order to increase comparability across samples, a cutoff criterion for infrequent words was established. In each language, outliers $(n=2$ Italians, $n=1$ German, $n=2$ English-Canadians, and $n=1$ French-Canadian) and terms produced by $20 \%$ or less of the sample were excluded. An outlier was defined as a data point that is located outside the fences ("whiskers") of the boxplot (outside 1.5 times the interquartile range above the upper quartile and below the lower quartile) (see Tables 2, 3, 4, and 5 for a complete list of items divided into the aforementioned categories in each language). The discrepancy in the number of items across questionnaires (Italian version $=67$ items, German version $=60$ items, English version $=75$ items, and French version $=64$ items) and categories was addressed by using the proportion of words produced in each category relative to the total number of words in the category.

\section{Results}

The descriptions for ISLQ scores in each language can be found in Table 1. 
TABLE 1: Descriptions of study measures.

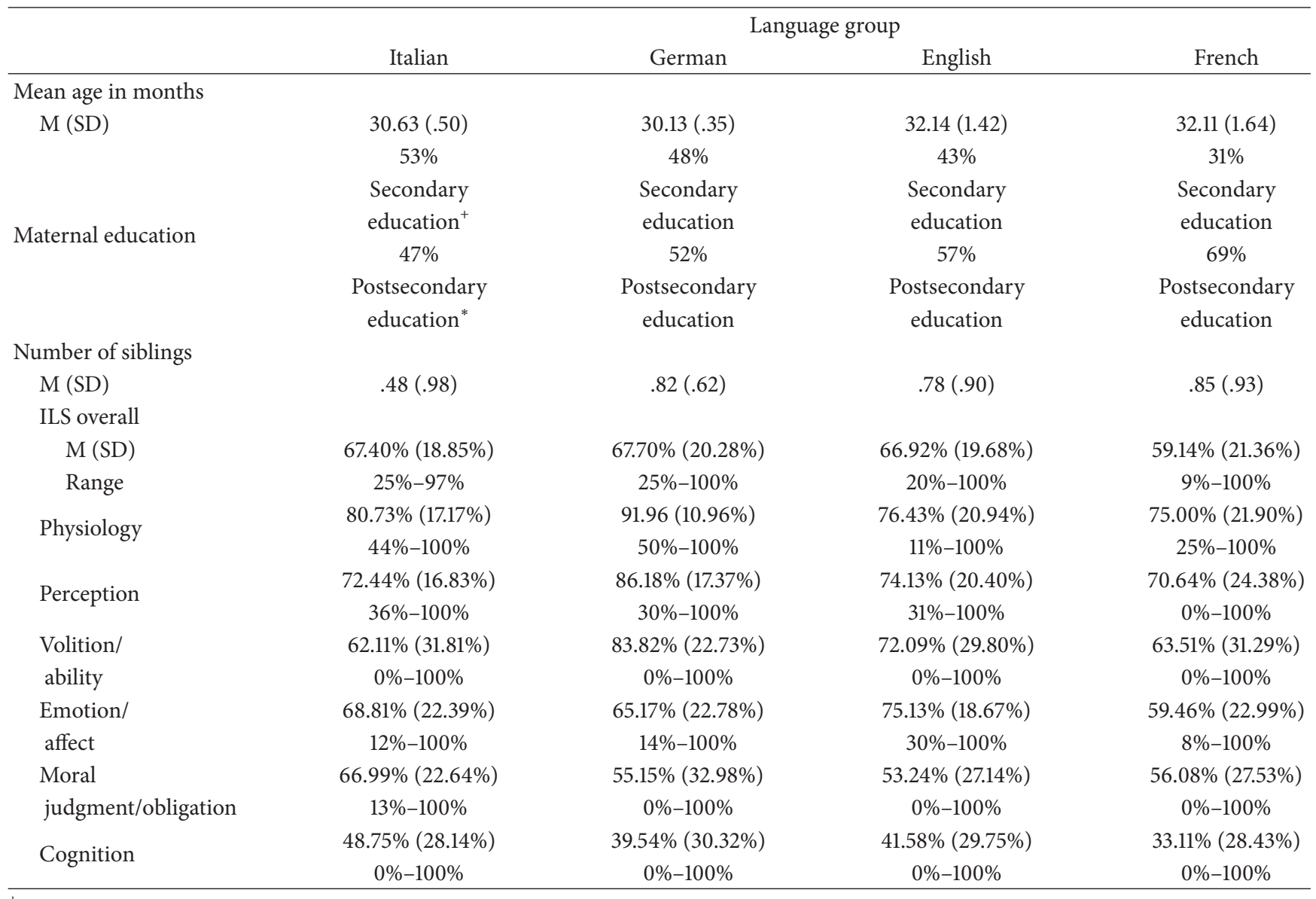

${ }^{+}$High-school diploma/A-levels.

*Bachelor's/Master's degree.

The main objective of the present study was to compare children's overall ISL scores across languages, in order to explore crosslinguistic consistency. In order to explore the amount of children's internal state language across languages, a one-way ANCOVA with language group (Italian, German, English, or French) as independent variable and children's overall ISL percentage scores as dependent variable was conducted. Preliminary point-biserial and Pearson productmoment correlation analyses (all two-sided) revealed no significant effect of age on children's ISL scores, while child gender ( $P$ ranging from 0.00 to 0.65 across languages), number of siblings ( $P$ ranging from 0.02 to 0.60 ), and maternal educational level ( $P$ ranging from 0.02 to 0.92 ) significantly influenced ISL scores. Thus, these factors were entered as covariates into the analysis. The effect of language group on children's overall ISL scores (65.26\%) was not significant: $F(3,279)=2.27, P=0.08$, and $\eta^{2}=0.02$. To assess the relative mastery of physiological $(80.49 \%)$, perceptual $(75.66 \%)$, volitional/ability (70.49\%), emotion/affect (67.59\%), moral judgment/obligation (57.35\%), and cognition (40.55\%) items, a $6 \times 2$ mixed model ANOVA with category as within-subject factor and gender as between-subject factor was conducted. A significant main effect of category, $F(5,1475)=227.91$, $P=0.00$, and $\eta^{2}=0.64$, emerged, but no significant main effect of gender was noted. Thus gender was not accounted for in subsequent analyses.

Post hoc pairwise comparison with Bonferroni adjustment revealed that children used more physiological terms $(80.49 \%)$ than terms from any other category. Further, they used significantly fewer $(P<0.001)$ perceptual terms $(75.66 \%)$ than physiological terms, while they used more terms (all $P<0.001$ ) from the perception category than terms from any other category (all $P<0.05$ ), except physiology terms. No significant differences between volition/ability (70.49\%) and emotion/affect (67.59\%) scores emerged. However, children had significantly higher (all $P<0.001$ ) volition/ability and emotion/affect scores than moral obligation scores (57.35\%). Finally, children produced significantly fewer (all $P<0.001)$ cognition terms (40.55\%) than terms from any other category.

To explore the relative distribution of internal state terms across categories in each language, ANOVAs with one withingroup variable (category) and the proportion of produced words in each category as the dependent variable were conducted separately for each language. In the Italian sample, a significant main effect of category $(F(5,315)=30.47$, $P=0.00$, and $\eta^{2}=0.33$ ) was revealed. Post hoc analyses with Bonferroni corrections indicated that Italian toddlers 
TABLE 2: Italian questionnaire (Questionario per Linguaggio Mentale).

\begin{tabular}{|c|c|c|c|c|c|}
\hline Percezione & Fisiologia & Emozione/Affettività & Aspirazione/Abilità & Cognizione & Moralità/Obbligazione \\
\hline Vedere & Avere fame & Felice & Volere & Sapere & Buono \\
\hline Osservare & Avere sete & Divertente & Dovere & Pensare & Brutto \\
\hline Udire & Avere sonno & Sentirsi (bene, & Potere & Credere & Capriccioso \\
\hline Farsi male & Dormire & male) & Ardere & Ricordare & Potere \\
\hline Ascoltare & Addormentato & Male (sentirsi male) & & Dimenticare & Lasciare \\
\hline Assagiare & Stanco & Meglio & & Forse & Essere supposto \\
\hline Odorare & Sveglio & Bene & & Capire & Essere obbligato \\
\hline Sentire & Svegliarsi & Bene (sentirsi & & Fingere & \\
\hline Freddo & Malato & bene) & & Sognare & \\
\hline Congelarsi & & Simpatico & & Indovinare & \\
\hline Caldo & & Mi Piace & & & \\
\hline Scottare & & Amare & & & \\
\hline Bollente & & Scherzare & & & \\
\hline \multirow[t]{12}{*}{ Bruciare } & & Triste & & & \\
\hline & & Furibondo & & & \\
\hline & & Spaventato & & & \\
\hline & & Pauroso & & & \\
\hline & & Disordinato & & & \\
\hline & & Schifoso & & & \\
\hline & & Sporco & & & \\
\hline & & Abbracciare & & & \\
\hline & & Baciare & & & \\
\hline & & Ridere & & & \\
\hline & & Sorridere & & & \\
\hline & & Piangere & & & \\
\hline
\end{tabular}

TABLE 3: German questionnaire (Fragebogen für den Internalen Wortschatz).

\begin{tabular}{|c|c|c|c|c|c|}
\hline Perzeption & Physiologie & Emotion/Affekt & Volition/Fähigkeiten & Kognition & Moral/Obligation \\
\hline Sehen & Hungrig & Glücklich & Wollen & Wissen & Gut \\
\hline Anschauen & Durstig & Lustig & Brauchen & Glauben & Schlecht \\
\hline (Zu)hören & Müde & Fühlen (gut, schlecht) & Möchte & Vergessen & Gemein \\
\hline Weh tun & Schlafen & Schlecht (fühlen) & Können & Vielleicht & Dürfen \\
\hline Schmecken & (Auf)wach(en) & In Ordnung sein & Schwer (zu tun) & Verstehen & Lassen \\
\hline Riechen & Schlecht sein & Besser & & So tun als ob & Müssen \\
\hline Anfühlen & & Gut (fühlen) & & Träumen & Können \\
\hline Frieren & & Ok & & Echt & Sollen \\
\hline Heiß & & Nett & & Raten & \\
\hline \multirow[t]{13}{*}{ Warm sein } & & Mögen & & & \\
\hline & & Lieben & & & \\
\hline & & Traurig & & & \\
\hline & & Ärgerlich & & & \\
\hline & & Angst (haben) & & & \\
\hline & & Gruselig & & & \\
\hline & & Schmutzig & & & \\
\hline & & Chaotisch & & & \\
\hline & & Eklig & & & \\
\hline & & Umarmen & & & \\
\hline & & Küssen & & & \\
\hline & & Lachen & & & \\
\hline & & Weinen & & & \\
\hline
\end{tabular}


TABLE 4: English questionnaire (Internal State Language Questionnaire).

\begin{tabular}{|c|c|c|c|c|c|}
\hline Perception & Physiology & Emotion/Affect & Volition/Ability & Cognition & Moral Judgment/Obligation \\
\hline See & Hungry & Happy & Want & Know & Good \\
\hline Look & Thirsty & Have fun & Need & Think & $\mathrm{Bad}$ \\
\hline Watch & Sleepy & Funny & Have to & Remember & Naughty \\
\hline Hear & Sleep & Feel (good, bad) & Can & Forget & May \\
\hline Hurt & Asleep & Bad (feel bad) & Hard (to do) & Maybe & Let \\
\hline Listen & Tired & To be all right & & May & Supposed to \\
\hline Taste & Awake & Better & & Understand & Have to \\
\hline Smell & Wake up & Good (feel good) & & Pretend & Should \\
\hline Feel (soft, warm) & Sick & O.K. & & Dream & Can (for permission) \\
\hline Cold (feeling cold) & & Nice & & Real & \\
\hline Freezing & & Like & & Guess & \\
\hline Hot (same as for cold) & & Love & & Mean & \\
\hline \multirow{15}{*}{ Warm (same as for cold) } & & Have a good time & & & \\
\hline & & Surprised & & & \\
\hline & & Sad & & & \\
\hline & & Angry & & & \\
\hline & & Mad & & & \\
\hline & & Scared & & & \\
\hline & & Scary & & & \\
\hline & & Dirty & & & \\
\hline & & Messy & & & \\
\hline & & Yucky & & & \\
\hline & & Hug & & & \\
\hline & & Kiss & & & \\
\hline & & Laugh & & & \\
\hline & & Smile & & & \\
\hline & & Cry & & & \\
\hline
\end{tabular}

produced significantly more physiology items (80.73\%) than items from any other category (all $P<0.01$ ), while they produced as many terms from the volition category $(62.11 \%)$ as from the perception (72.44\%), emotion/affect $(68.81 \%)$, and moral judgment/obligation (66.99\%) categories. Finally, they produced significantly fewer cognition terms $(48.75 \%)$ than terms from any other category (all $P<0.01$ ).

In the German sample, the main effect of category $\left(F(5,335)=116.72, P=0.00\right.$, and $\left.\eta^{2}=0.63\right)$ was significant. Post hoc analyses with Bonferroni corrections indicated that German toddlers produced significantly more physiology items (91.67\%), perception items (83.82\%), and volition items $(86.18 \%)$ than emotion/affect terms $(65.17 \%)$, moral judgment/obligation terms (55.15\%), and cognition terms $(39.54 \%)$ (all $P<0.001)$. Further, children produced more terms from the emotion category than from the moral judgment/obligation category (all $P<0.001$ ). Consistent with children speaking Italian, children speaking German produced significantly fewer items from the cognition category than from any other category (all $P<0.001$ ).

In English-Canadian children, a significant main effect of category $\left(F(5,450)=87.13, P=0.00\right.$, and $\left.\eta^{2}=0.49\right)$ emerged. English-speaking toddlers produced significantly more terms from the physiology (76.43\%), volition $(72.09 \%)$, perception $(74.13 \%)$, and emotion/affect $(75.13 \%)$ categories than from the moral judgment/obligation category $(53.24 \%)$ and cognition category (41.58\%) (all $P<0.001$ ). Their production of cognition terms lagged significantly behind their production of terms from all other categories (all $P<$ 0.001).

A significant main effect of category also emerged in the French-Canadian sample $(F(5,315)=30.47, P=0.00$, and $\left.\eta^{2}=0.33\right)$. French-speaking children produced more terms from the physiology category $(75.00 \%)$ than from the volition $(63.51 \%)$, emotion/affect $(59.46 \%)$, moral judgment/obligation (56.08\%), and cognition (33.11\%) categories (all $P<0.001)$. Children's perception scores $(70.64 \%)$ did not differ significantly from their physiology and volition scores. However, while children's volition, emotion/affect, and moral judgment/obligation scores did not differ significantly from each other, children's perception scores were significantly higher than children's emotion/affect and moral judgment/obligation scores (all $P<0.001$ ). Consistent with the findings in the other languages, French-speaking children were found to produce significantly fewer terms from the cognition category than terms from all other categories (all $P<0.001)$. 
TABLE 5: French questionnaire (Questionnaire sur le Langage des États Mentaux).

\begin{tabular}{|c|c|c|c|c|c|}
\hline Perceptif & Physiologique & Émotionnel/Affectif & Intentionnalité/Habileté & Cognitif & $\begin{array}{l}\text { Jugement } \\
\text { Moral/ } \\
\text { Obligations }\end{array}$ \\
\hline Voir & Faim (j’ai faim) & Heureux & Vouloir & Savoir & Bon \\
\hline Regarder & Soif (j'ai soif) & S’amuser/Avoir du & Besoin (j’ai besoin) & Penser & Mauvais \\
\hline Entendre & Dormir (je & fun & Pouvoir (je peux) & Rappeler/ Souvenir (se & Méchant/Vilain \\
\hline Écouter & m’endors) & Drôle & Difficile, dur & rappeler de) & $\begin{array}{l}\text { Pouvoir (capacité } \\
\text { de) }\end{array}$ \\
\hline Fait mal & Dormir (je ne & Fier (être fier de) & (c'est difficile) & Oublier & Laisser \\
\hline Sentir & veux pas & Sentir (bien, mal) & & Peut-être & $\begin{array}{l}\text { Pouvoir } \\
\text { (est-que je peux?) }\end{array}$ \\
\hline Goûter & dormir) & Mal (je me sens mal) & & Comprendre & \\
\hline Toucher & Fatigué & Aller bien (est-ce que tu vas bien?) & & Faire semblant & \\
\hline (c'est doux, & Éveillé/Réveillé & Mieux & & Rêver & \\
\hline c'est chaud) & (je suis éveillé) & Bien (ex. Se sentir bien) & & Vrai & \\
\hline Avoir froid & Se réveiller & Correct (Danny est correct) & & Dire (je veux dire) & \\
\hline Gelé & Malade & Gentil & & & \\
\hline \multirow[t]{14}{*}{ Avoir chaud } & & Aimer (quelqu'un) & & & \\
\hline & & Aimer (quelque chose) & & & \\
\hline & & Avoir du fun & & & \\
\hline & & Surpris & & & \\
\hline & & Triste & & & \\
\hline & & Fâché & & & \\
\hline & & Faire peur (j’ai eu peur) & & & \\
\hline & & Sale & & & \\
\hline & & Dégoutant, dégueulasse & & & \\
\hline & & Caresser & & & \\
\hline & & Embrasser & & & \\
\hline & & Rire & & & \\
\hline & & Sourire & & & \\
\hline & & Pleurer & & & \\
\hline
\end{tabular}

\section{Discussion and Conclusions}

This large-scale crosslinguistic study of toddlers' expressive vocabulary for internal states essentially confirms and extends the findings of previous Anglo-American research [4] and research in French- and English-Canadian children $[1,9]$. Consistent with research on children's ToM [12], showing that an understanding of desires precedes an understanding of beliefs in preschoolers across different cultures, the current study shows that, in toddlers, talk about desires is more varied than talk about beliefs at 30 to 32 months.

Children's overall mastery of expressions for internal states was remarkably consistent across the four linguistic groups. Furthermore, regardless of their mother tongue, all infants produced fewer cognition terms than any other mental state language categories. Thus, the ISLQ can be considered a potential measure for the global assessment of ToM skills in toddlerhood, a developmental period for which there is no available battery of theory of mind tasks.
In addition, across all four languages, as well as across gender, expressions for physiological states were among the most varied, followed by expressions of perceptual states, volitional states and abilities, emotional states, and moral judgments and obligations. Finally, children's vocabulary for purely mental and abstract entities proved to be the least varied. This developmental sequence, from mastery of relatively tangible physiological states to that of epistemic concepts, corresponds to the increase of inner experiencerelated utterances against the decrease of object-related utterances in general language development [13]. Specifically, in all languages, children's desire vocabulary was significantly more varied than their vocabulary for epistemic state terms (e.g., believe, know). While the current study provides no longitudinal evidence, the present data, based on a crosssectional design, appears to mirror the sequence of explicit understanding of these concepts. More specifically, a scale of theory of mind tasks tested both cross-sectionally and longitudinally across many languages and cultures revealed 
that diverse desire understanding consistently preceded children's comprehension of diverse and false beliefs $[2,6,12,14-$ 16]. One theoretical explanation is that desires are easier to grasp because they do not differ from reality. Cognitive state terms, however, typically mark a distinction between the actual state of affairs and the represented state of affairs and, thus, require metarepresentation (see Apperly et al. [17] for a discussion of belief-desire reasoning). Further, the finding of crosslinguistic consistency in children's overall internal state vocabulary fits crosslinguistic evidence that children's early internal state vocabulary is developmentally related to children's epistemic perspective-taking skills [1]. Taken together, these crosslinguistic results suggest that across languages internal state vocabulary develops during early childhood and is developmentally related to precursor abilities of a theory of mind, laying the ground for a fullfledged theory of psychological states.

Overall, while the present data support the conclusion that there is crosslinguistic similarity in toddlers' internal state vocabulary, we also observed few crosslinguistic discrepancies in regard to the patterns of individual internal state language categories. In comparison to German- and English- speaking children, Italians' and French-Canadians' use of desire terms was not quite as developed at 30 months of age relative to the emotion/affect and moral/obligation and cognition categories. This result is consistent with findings by Tardif and Wellman [10] who have demonstrated variation in the timing of the beginning and end points of the desirecognition sequence as a function of linguistic and cultural factors. For instance, there is cross-cultural evidence that individual differences in parent-child talk are associated with variation in internal state references [18-21]. Thus, parental input might account for slight crosslinguistic differences in children's internal state vocabulary and should be taken into account in crosslinguistic research. More specifically, cultural preoccupations might lead parents to use internal state language (e.g., desire and emotion talk) earlier and more consistently in some languages, in order to transmit certain culturally relevant concepts (e.g., individualism and kinship) to young children [22]. Thus, future research should compare not only children's, but also parent's internal state talk across different languages and cultural contexts. Further, since our results might only apply to normally developing middle-class children, it seems warranted to extend future crosslinguistic research and include socially diverse and clinical samples such as autistic children, who are impaired in both internal state talk and theory of mind [23]. This paper has compared Western cultures and Indo-European languages that are relatively close. Thus, it would be an interesting venue for future research to compare Western cultures to Eastern cultures or indigenous cultures. A cross-cultural study comparing ToM development in Chinese children and Englishspeaking children from Australia and the United States found commonalities as well as specific sociocultural differences [12]. The exact nature of these differences might depend very specifically on variability in internal state language use and other cultural factors. Further, languages from different language families should be compared. Finally, longitudinal studies should look at the developmental sequence of internal state language assessing children's skills at the developmental milestones of 24, 30, and 36 months. When used across different contexts, languages, and social groups, parent report data could effectively help to untangle the various proposals for how and when children's talk about the psychological world develops.

\section{Conflict of Interests}

The authors declare that there is no conflict of interests regarding the publication of this paper.

\section{Acknowledgments}

This research was supported by a Grant from the German Research Council (So 213/27-2) to Beate Sodian and by a Research Grant from the Social Sciences and Humanities Research Council of Canada (no. 435-2012-1403) to Diane Poulin-Dubois. This research was also supported by NICHD under Award no. R01HD468058 to Diane Poulin-Dubois and does not necessarily represent the views of the National Institutes of Health. Further, this research was supported by a Grant from the University of Chieti-Pescara to Tiziana Aureli. The authors thank the research assistants who helped with data collection and the children and parents for their participation.

\section{References}

[1] S. S. Chiarella, S. Kristen, D. Poulin-Dubois, and B. Sodian, "Concurrent Relations between perspective-taking skills, desire understanding, and internal-state vocabulary," Journal of Cognition and Development, vol. 14, no. 3, pp. 480-498, 2013.

[2] H. M. Wellman and D. Liu, "Scaling of theory-of-mind tasks," Child Development, vol. 75, no. 2, pp. 523-541, 2004.

[3] I. Bretherton, S. McNew, and M. Beeghly-Smith, "Early person knowledge as expressed in gestural and verbal communication: when do infants acquire a "theory of mind?'”' in Infant Social Cognition, M. Lamb and L. Sherrod, Eds., pp. 333-373, Hillsdale, New York, NY, USA, 1981.

[4] I. Bretherton and M. Beeghly, "Talking about internal states: the acquisition of an explicit theory of mind," Developmental Psychology, vol. 18, no. 6, pp. 906-921, 1982.

[5] M. Shatz, H. M. Wellman, and S. Silber, "The acquisition of mental verbs: a systematic investigation of the first reference to mental state," Cognition, vol. 14, no. 3, pp. 301-321, 1983.

[6] K. Bartsch and H. M. Wellman, Children Talk about the Mind, Oxford University Press, New York, NY, USA, 1995.

[7] L. A. Ferres, "Children's early theory of mind: Exploring the development of the concept of desire in monolingual Spanish children," Developmental Science, vol. 6, no. 2, pp. 159-165, 2003.

[8] B. Pascual, G. Aguado, M. Sotillo, and J. C. Masdeu, "Acquisition of mental state language in Spanish children: a longitudinal study of the relationship between the production of mental verbs and linguistic development," Developmental Science, vol. 11, no. 4, pp. 454-466, 2008.

[9] D. Poulin-Dubois, S. S. Chiarella, and A. Polonia, "Toddlers' vocabulary about the mind: a cross-linguistic study using the internal state language questionnaire," Rivista Di Psicolinguistica Applicata, vol. 9, no. 3, pp. 35-49, 2009. 
[10] T. Tardif and H. M. Wellman, "Acquisition of mental state language in Mandarin- and Cantonese-speaking children," Developmental Psychology, vol. 36, no. 1, pp. 25-43, 2000.

[11] K. M. Olineck and D. Poulin-Dubois, "Infants' ability to distinguish between intentional and accidental actions and its relation to internal state language," Infancy, vol. 8, no. 1, pp. 91100, 2005.

[12] H. M. Wellman, F. Fang, D. Liu, L. Zhu, and G. Liu, "Scaling of theory-of-mind understandings in Chinese children," Psychological Science, vol. 17, no. 12, pp. 1075-1081, 2006.

[13] E. Bates, V. Marchman, D. Thal et al., "Developmental and stylistic variation in the composition of early vocabulary," Journal of Child Language, vol. 21, no. 1, pp. 85-123, 1994.

[14] S. Kristen, C. Thoermer, T. Hofer, G. Aschersleben, and B. Sodian, "Skalierung von theory of mind aufgaben," Zeitschrift für Entwicklungspsychologie und Pädagogische Psychologie, vol. 38, no. 4, pp. 186-195, 2006.

[15] A. Shahaeian, C. C. Peterson, V. Slaughter, and H. M. Wellman, "Culture and the sequence of steps in theory of mind development," Developmental Psychology, vol. 47, no. 5, pp. 1239-1247, 2011.

[16] H. M. Wellman and J. D. Woolley, "From simple desires to ordinary beliefs: the early development of everyday psychology," Cognition, vol. 35, no. 3, pp. 245-275, 1990.

[17] I. A. Apperly, F. Warren, B. J. Andrews, J. Grant, and S. Todd, "Developmental continuity in theory of mind: Speed and accuracy of belief-desire reasoning in children and adults," Child Development, vol. 82, no. 5, pp. 1691-1703, 2011.

[18] S. le Sourn-Bissaoui and F. Hooge-Lespanol, "Maternal discourse, children's language and development of theory of mind," Psychology of Language and Communication, vol. 10, no. 1, pp. 5-19, 2006.

[19] D. Liu, H. M. Wellman, T. Tardif, and M. A. Sabbagh, “Theory of mind development in chinese children: a meta-analysis of false belief understanding across cultures and languages," Developmental Psychology, vol. 44, no. 2, pp. 523-531, 2008.

[20] M. Taumoepeau and T. Ruffman, "Mother and infant talk about mental states relates to desire language and emotion understanding," Child Development, vol. 77, no. 2, pp. 465-481, 2006.

[21] M. Taumoepeau and T. Ruffman, "Stepping stones to others' minds: Maternal talk relates to child mental state language and emotion understanding at 15, 24, and 33 months," Child Development, vol. 79, no. 2, pp. 284-302, 2008.

[22] N. Evans and S. C. Levinson, "The myth of language universals: language diversity and its importance for cognitive science," Behavioral and Brain Sciences, vol. 32, no. 5, pp. 429-492, 2009.

[23] M. Siller, M. R. Swanson, G. Serlin, and A. G. Teachworth, "Internal state language in the storybook narratives of children with and without autism spectrum disorder: investigating relations to theory of mind abilities," Research in Autism Spectrum Disorders, vol. 8, no. 5, pp. 589-596, 2014. 

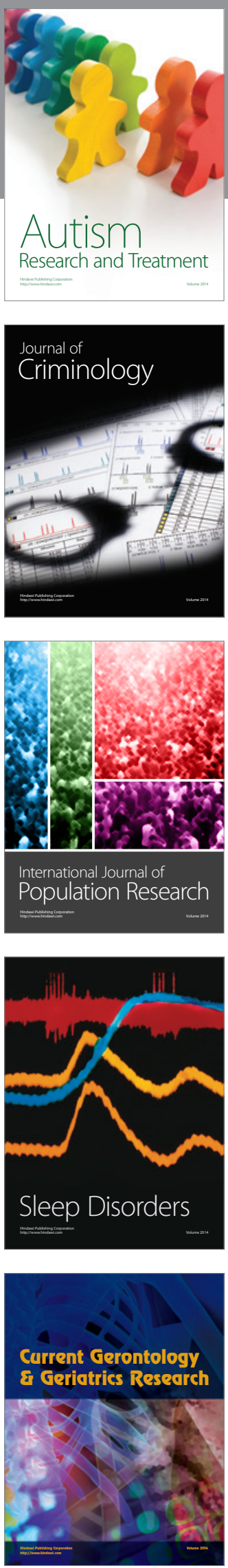
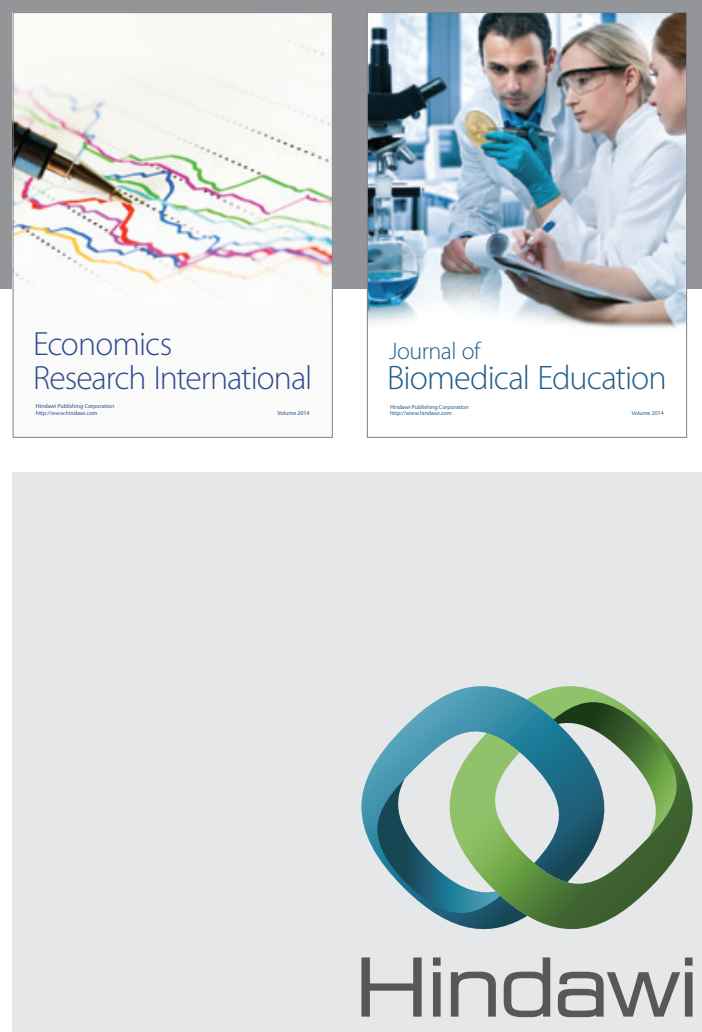

Submit your manuscripts at

http://www.hindawi.com
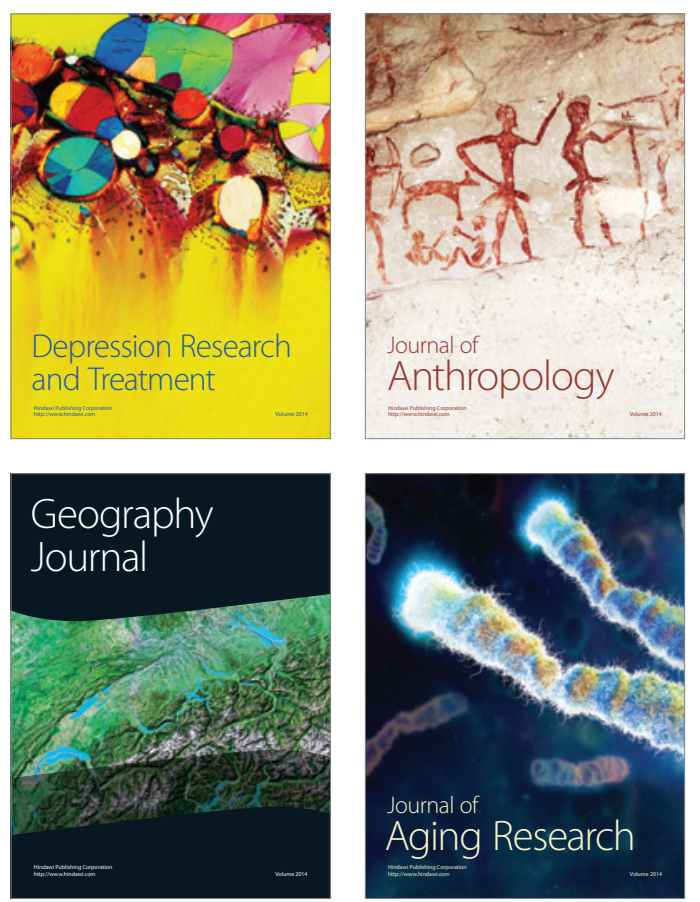
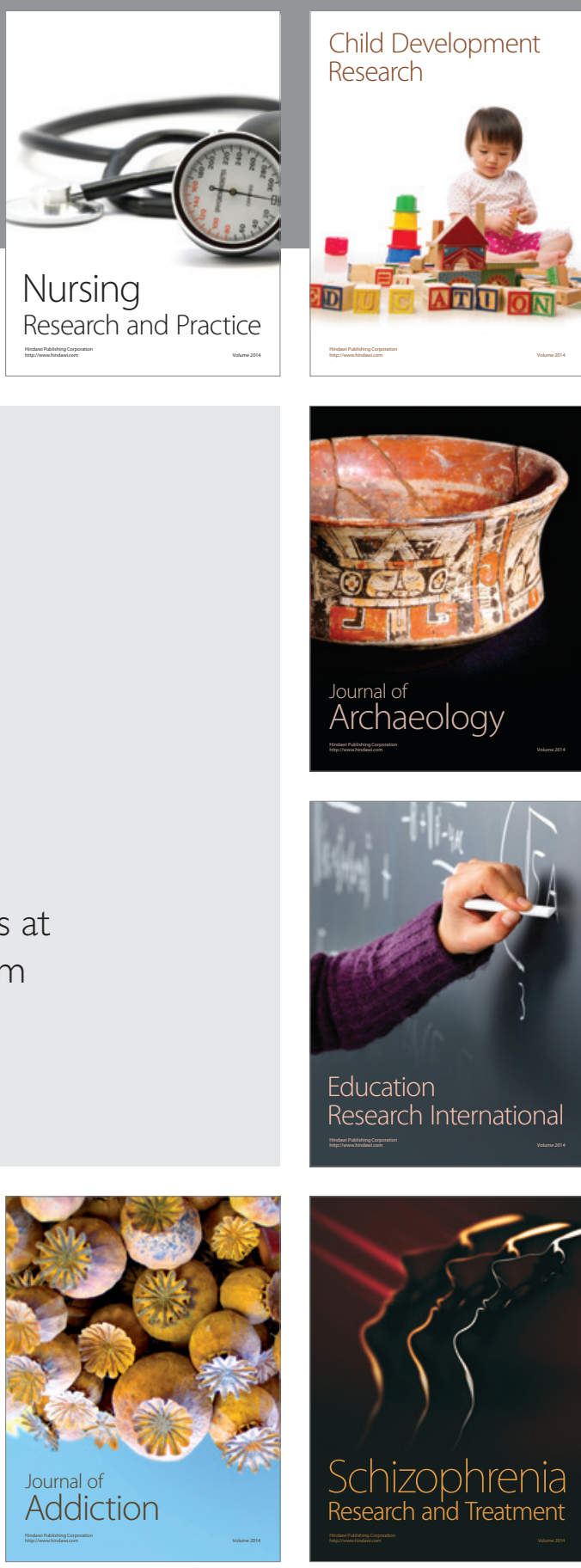

(D)
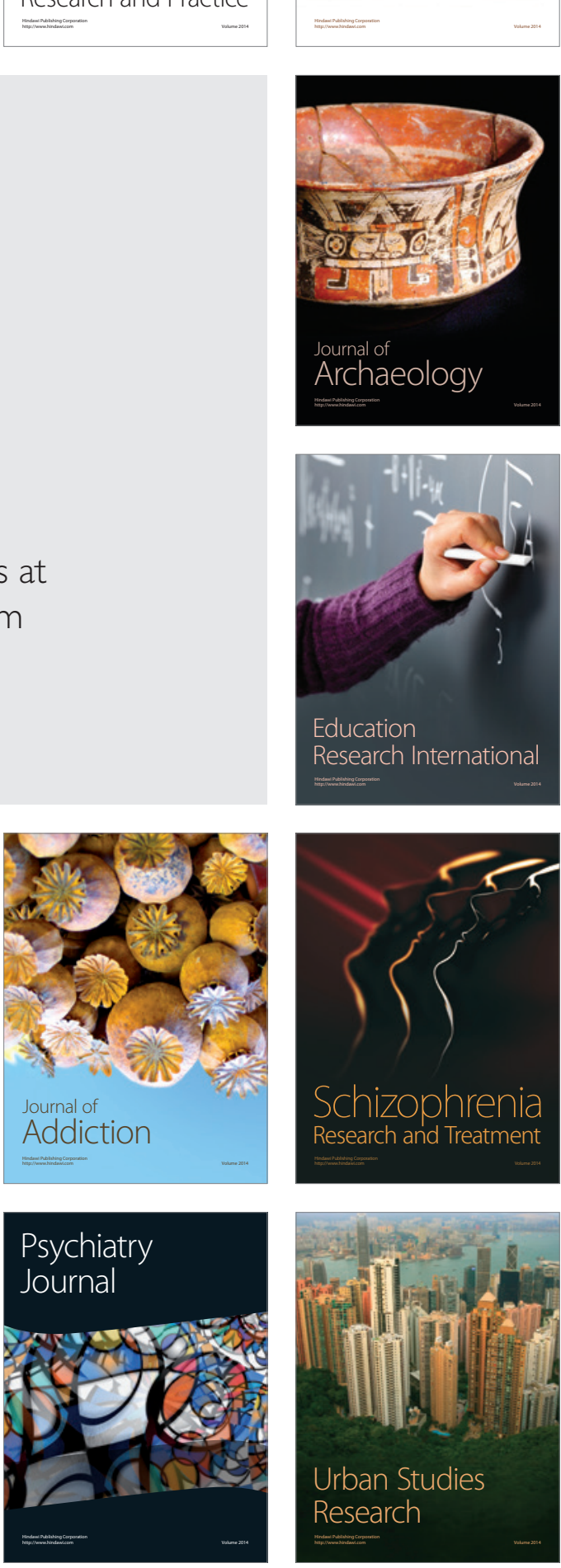